\title{
DIAGNÓSTICO DA ÁREA DE PRESERVAÇÃO PERMANENTE DE UM TRECHO DE AFLUENTE DO RIO SOROCABA
}

Priscila Aiko Someda Dias ${ }^{1}$, Ana Flávia Francisconi ${ }^{2}$, Carla Américo ${ }^{2}$, Liamara Santos Masullo ${ }^{2^{*}}$, Thaís Cristina Ferreira Silva ${ }^{2}$

${ }^{1}$ Graduanda em Engenharia Florestal pela Universidade Federal de São Carlos *liamaramasullo@usp.br

${ }^{2}$ Bacharel em Engenharia Florestal pela Universidade Federal de São Carlos

Recebido em: 03/10/2016 - Aprovado em: 21/11/2016 - Publicado em: 05/12/2016 DOI: 10.18677/EnciBio 2016B 035

\begin{abstract}
RESUMO
Matas ciliares são essenciais para a proteção de recursos hídricos em uma microbacia hidrográfica. Contudo, o crescimento urbano gera pressões antrópica sobre estas áreas, levando a degradação dos recursos naturais. A recuperação de áreas degradadas é uma importante ferramenta para garantir os benefícios hidrológicos e ecológicos propiciados pelas matas ripárias. Assim, o presente trabalho visa diagnosticar as condições da área de preservação permanente (APP) de um afluente do Rio Sorocaba no Bairro Morumbi, Sorocaba - SP e indicar áreas passíveis de recuperação. A área selecionada apresenta, aproximadamente, 10 hectares e o córrego $1,7 \mathrm{~km}$ de extensão. Sistema de informação geográfico (SIG) foi utilizado para determinar a cobertura atual do solo e para elaborar os mapas de adequação legal da área. O diagnóstico da APP foi realizado por meio de visitas de campo e análises de mapas. Nas visitas de campo foram feitas observações das características do solo, da composição de espécies predominantes e do potencial de regeneração natural da área. Este levantamento mostrou que há potencial de regeneração, apesar de que cinco das sete espécies encontradas serem exóticas do bioma. No mapeamento verificou-se que $13 \%$ da área da APP se encontra impermeabilizada, e $63 \%$ com cobertura vegetal, sendo as demais áreas consideradas como prioritárias para a recuperação.
\end{abstract}

PALAVRAS-CHAVE: APP, Mata Ciliar; Sorocaba

\section{ENVIRONMENTAL DIAGNOSIS OF PERMANENT PRESERVATION AREA (PPA) FOR A TRIBUTARY OF THE SOROCABA RIVER}

\footnotetext{
ABSTRACT

Riparian forests are essential for the protection of water resources in a watershed. However, urban growth generates anthropogenic pressures on these areas, leading to degradation of natural resources. The recovery of degraded areas is an important tool to ensure the hydrological and ecological benefits provided by riparian forests. Therefore, the present study aims to diagnose the conditions of Permanent Preservation Area (PPA) in a tributary of the Rio Sorocaba in district Morumbi, Sorocaba - SP and indicate areas that are possible for recovery. The selected area has approximately 10 hectares and the stream has about $1.7 \mathrm{~km}$ of extension. We used Geographic Information System (GIS) to determine the current land use and ENCICLOPÉDIA BIOSFERA, Centro Científico Conhecer - Goiânia, v.13 n.24; p.382 2016
} 
make maps of the legal compliance of the area. To prepare the proposal for recovery we made a diagnosis of the area and literature review. In field visits were made analyzes about soil characteristics, species survey and potential of natural regeneration in the area. In the diagnosis, we observed that there is high potential for regeneration, and that five of the seven species found are exotic. Around $13 \%$ of the APP area is waterproofed, $63 \%$ is covered by forest, being the other areas considered priority areas for recovery.

KEYWORDS: Riparian forests; Sorocaba; PPA.

\section{INTRODUÇÃO}

O crescimento de áreas urbanas estimula a competição por recursos ambientais, como solo e água (TUCCI, 2008). A intensificação da demanda por tais recursos tem conduzido à mudança do uso e cobertura do solo (VALENTE \& VETTORAZZI, 2008). Essa alteração de uso da terra pode causar severos impactos ambientais, como intensificação de processos erosivos, alterações hidrológicas, declínio da biodiversidade, diminuição da disponibilidade de água e desertificação (FENGLER et al., 2015).

O município de Sorocaba está entre as dez maiores economias do Estado, isto é atribuído ao seu amplo parque industrial e ao seu forte setor de serviços (SEADE, 2010). O crescimento urbano da região se intensificou no início do século XIX, com a produção de algodão, a inauguração da estrada de ferro sorocabana e o aumento das indústrias têxteis. Neste período, uma expansão da infraestrutura urbana levou ao adensamento das áreas centrais, e à criação de novos bairros nas margens dos seus principais rios (FREY, 2011).

As principais causas de degradação das matas ciliares são o desmatamento para expansão de áreas cultivadas e urbanas, o uso incorreto do solo e da paisagem, e a ausência de planejamento urbano (PINTO et al., 2012). A falta de planejamento na ocupação de uma bacia hidrográfica pode interferir no balanço hídrico em diferentes escalas, gerando impactos negativos, principalmente, sobre a qualidade e disponibilidade da água (CHAVES \& SANTOS, 2009).

Um dos grandes desafios do homem para a conservação ambiental é concentrar esforços e recursos para preservação e recuperação de áreas naturais estratégicas. As Áreas de Preservação Permanentes (APP's) se destacam devido as funções hidrológicas e ecológicas que desempenham, e por isto são consideradas essenciais dentro de uma microbacia hidrográfica (MAGALHÃES \& FERREIRA, 2000). A função ambiental das APP's é preservar os recursos hídricos, a paisagem, a estabilidade geológica, a biodiversidade, e o fluxo gênico de fauna e flora, além de proteger o solo e assegurar o bem-estar das populações humanas (CONAMA, 2006).

A mata ciliar é um elemento importante para a resiliência da microbacia (ATTANASIO et al., 2011). Essas áreas são essenciais na busca da sustentabilidade ambiental, pois promovem a estabilidade das margens dos rios e proporcionam microclima ribeirinho favorável ao aumento da biodiversidade e do equilíbrio dos ecossistemas ripários (FELIPE et al., 2015). Desta forma, o seu reflorestamento tem sido apontado como uma das soluções factíveis para a questão da produção de água (PHUA; MINOWA, 2005). Por meio de ações técnicas, áreas alteradas pelo homem são recuperadas para mitigar os efeitos negativos da degradação ambiental (GOLDEMBERG \& BARBOSA, 2004) e garantir os benefícios sobre qualidade e quantidade de água produzida na bacia hidrográfica. 
Neste contexto, o presente estudo teve como objetivo realizar um diagnóstico ambiental da APP de um afluente do rio Sorocaba e indicar as áreas passíveis de recuperação da vegetação.

\section{MATERIAL E MÉTODOS}

\section{Localização e caracterização da área}

A área se encontra no município de Sorocaba (bairros: Jardim Leocádia e Jardim Morumbi), delimitado pelas coordenadas: 2327'58,65" a 2328'28,22" latitudes Sul e 4725'44,74" a 4726'30,53" longitu des Oeste (Figura 1).

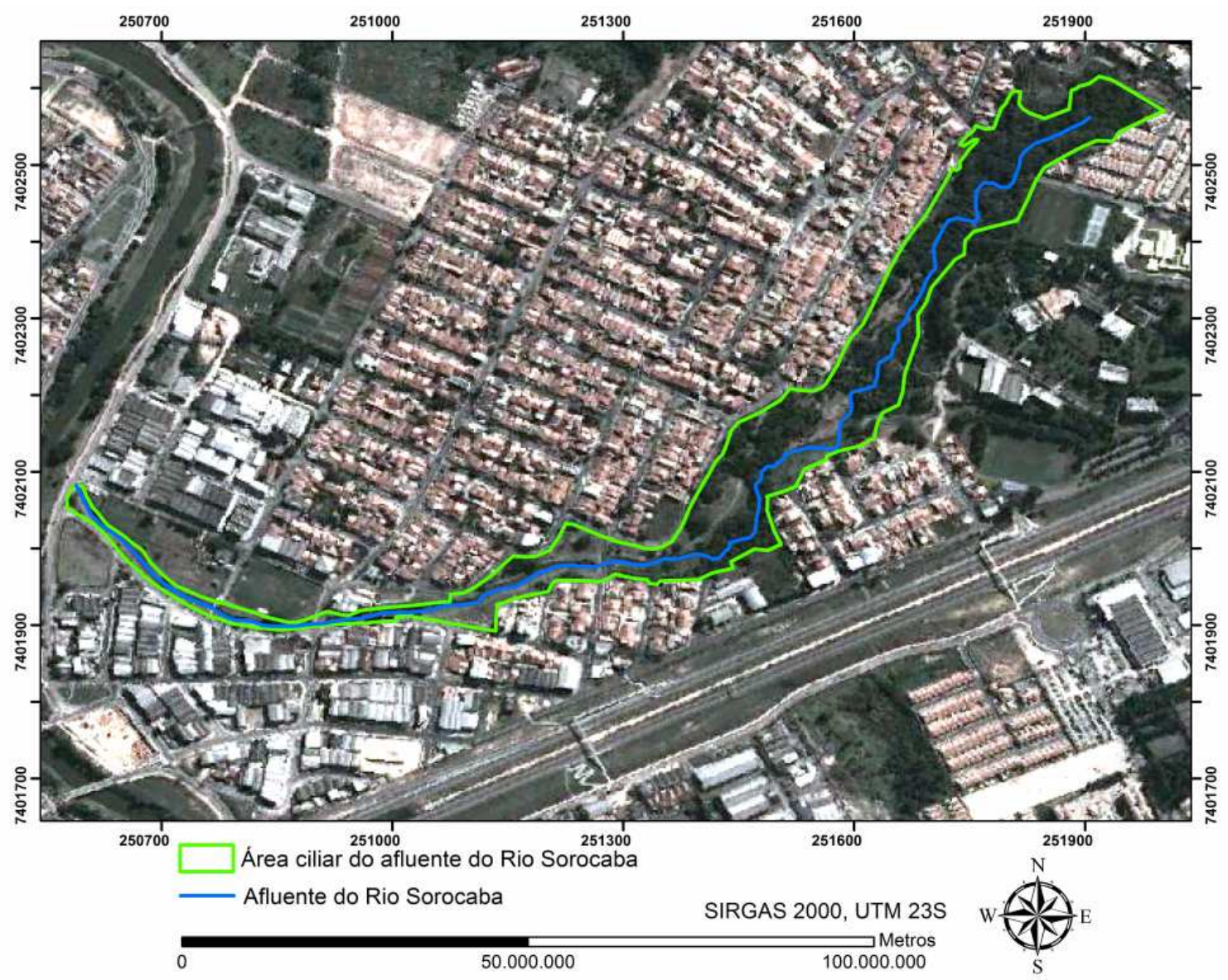

FIGURA 1. Localização da área para a proposta de recuperação de Área de Preservação Permanente Sorocaba - SP. (Elaboração: autores)

O município de Sorocaba está situado na porção sudeste do Estado de São Paulo. Possui uma área territorial de $449 \mathrm{~km}^{2}$, e uma população de cerca de $610 \mathrm{mil}$ habitantes, concentrada $98 \%$ em zona urbana. Da área total, $81,5 \%$ se constitui em área urbana, e 18,5\% em área rural (SEADE, 2010). O território do município é marcado por uma densa e perene malha hídrica. Com quase três mil nascentes, a região conta com dezenas de córregos, e alguns rios, dos quais o Rio Sorocaba e o Rio Pirajibu se destacam pelas maiores vazões (Prefeitura de Sorocaba, 2010b).

Os solos predominantes da região são Argissolos e Latossolos, embora ocorram Cambissolos, Neossolos Litólicos e Quartzarênicos em algumas porções do ENCICLOPÉDIA BIOSFERA, Centro Científico Conhecer - Goiânia, v.13 n.24; p.384 2016 
município (MADEIRA, 2001). Geologicamente, o município se localiza sobre os limites da Bacia Sedimentar do Paraná e do Embasamento Cristalino. Em termos geomorfológicos, está situada na borda da Depressão Periférica Paulista (AB'SABER, 1958).

O clima da região é do tipo subtropical quente "Cfa" (SCORIZA \& PIÑARODRIGUES, 2014), com temperatura média anual de $21,4^{\circ} \mathrm{C}$ e precipitação anual de $1.285 \mathrm{~mm}$. A formação vegetal é a Floresta Estacional Semidecidual (FES) com zonas de contato (ecótono) com formações de cerrado. Apenas $12 \%$ da vegetação original (5,7 mil hectares) do município ainda se mantêm pouco alterada, concentradas, principalmente, nas regiões mais afastadas e em Áreas de Preservação Permanente (Prefeitura de Sorocaba, 2010a).

\section{Diagnóstico e mapeamento da área}

\section{Levantamento florístico}

O Levantamento de espécies foi realizado por meio da classificação de indivíduos arbóreos e gramíneas predominantes, que se encontravam a uma distância de 30 metros de ambas as margens do córrego, conforme a Lei № 12.651 de 2012. Para isto, as árvores foram identificadas in loco, método utilizado por outros autores (CIELO FILHO \& SANTIN, 2002; SOUZA et al., 2011; RICHTER et al. 2012), utilizando bibliografia específica de apoio. Para espécies que não puderam ser identificadas imediatamente foram retiradas amostras vegetativas (folhas e galhos), e quando possível, frutos e flores para posterior identificação.

Com essas informações realizou-se um levantamento bibliográfico das espécies encontradas, suas ocorrências naturais, biologia reprodutiva e grupo ecológico. As síndromes de dispersão (VAN DER PIJL, 1982) foram classificadas em i) zoocóricas - dispersas por animais, ii) anemocóricas - dispersas pelo vento e iii) autocóricas - auto-dispersão. Os grupos ecológicos (SWAINE \& WHITMORE, 1988) foram classificados em i) espécies pioneiras - espécies que tem suas sementes germinadas em dossel aberto; e ii) espécies não pioneiras - espécies que podem germinar na sombra, suas plântulas são encontradas sob dossel, mas podem também ser encontradas em ambientes abertos (MACIEL et al., 2003). As ocorrências de espécies foram classificadas em i) nativas regional - a espécie possui distribuição natural do bioma; i) nativa do Brasil - apesar de não pertencer ao bioma regional possui ocorrência no território brasileiro; e iii) exótica - espécies introduzidas que não apresentam distribuição natural no Brasil.

\section{Mapas de uso e cobertura do solo e de adequação legal}

Os mapas foram gerados a partir do diagnóstico de campo e da fotointerpretação de imagens de satélite. Neles foram identificados os usos atuais, as áreas de vegetação ao longo do curso d'água a serem conservadas e as áreas prioritárias para a recuperação da área de APP. As classificações utilizadas são: i) Classe 1 - área de uso urbano e industrial com impermeabilização do solo; Classe 2 - áreas com remanescentes arbóreos e/ou com grande quantidade de plântulas regenerantes; Classes 3 - áreas de solo exposto com indícios e/ou potencial de erosão; e Classe 4 - áreas recobertas por gramíneas exóticas. As áreas prioritárias foram definidas como aquelas sem cobertura vegetal sofrendo processos erosivos 
(Classe 3) e/ou cobertas por gramínea (Classe 4), isto é, as áreas sem cobertura florestal com potencial para a revegetação.

Para determinação do uso e cobertura do solo foram utilizadas: a carta planialtimétrica do Instituto Brasileiro de Geografia e Estatística (IBGE) para o Município de Itu (código: SF-23-Y-C-II-3) que abrange a porção nordeste da cidade de Sorocaba, e imagens de satélite Digital Globe, obtidas por meio do programa Google Earth na resolução de 100 metros. As imagens e os mapas foram processados utilizando o software ArcGIS, versão 9.3.

\section{RESULTADOS E DISCUSSÃO}

\section{Diagnóstico da área}

A APP apresenta aproximadamente 10 hectares e o afluente do Rio Sorocaba cerca de $1,7 \mathrm{~km}$ de extensão. Apesar da grande quantidade de fragmentos florestais e da rica hidrografia, a área está inserida numa matriz urbana-industrial na qual existem graus variados de pressão antrópica (Figura 2).

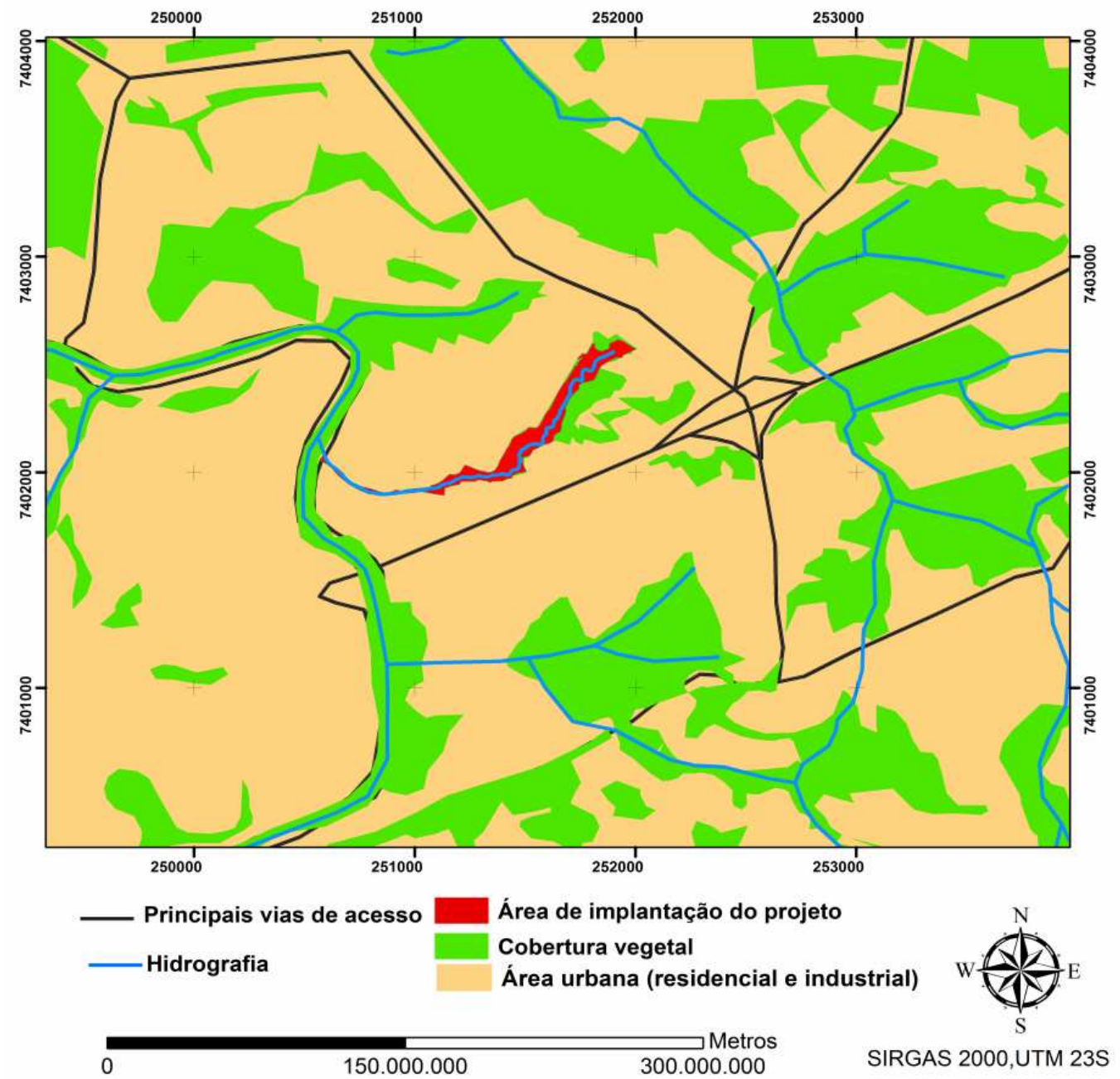

FIGURA 2. Área de implantação do projeto de recuperação de um afluente do Rio Sorocaba, no município de Sorocaba - SP. (Elaboração: autores)

\section{Conservação do solo e qualidade da água}

A retirada da vegetação ao longo do córrego tornou suas margens frágeis e o solo mais suscetível à erosão, ocasionando o assoreamento em alguns trechos ENCICLOPÉDIA BIOSFERA, Centro Científico Conhecer - Goiânia, v.13 n.24; p.386 
(Figura 3a). Em diversos pontos ao longo do curso do córrego, observou-se a presença de tubulações expostas (Figura 3c) e trechos com vazão reduzida, praticamente secos nas áreas cuja ocupação urbana é mais intensa e não há cobertura florestal em suas margens (Figura $3 b$ ). $O$ mesmo foi encontrado por PEREIRA et al. (2014), os quais verificaram que a redução da cobertura vegetal ao longo do tempo na bacia hidrográfica implicou no assoreamento e na redução do volume das águas do rio estudado. Esses autores, enfatizam a importância do monitoramento e manutenção de remanescentes de floresta nativa para a contínua produção de água de qualidade.
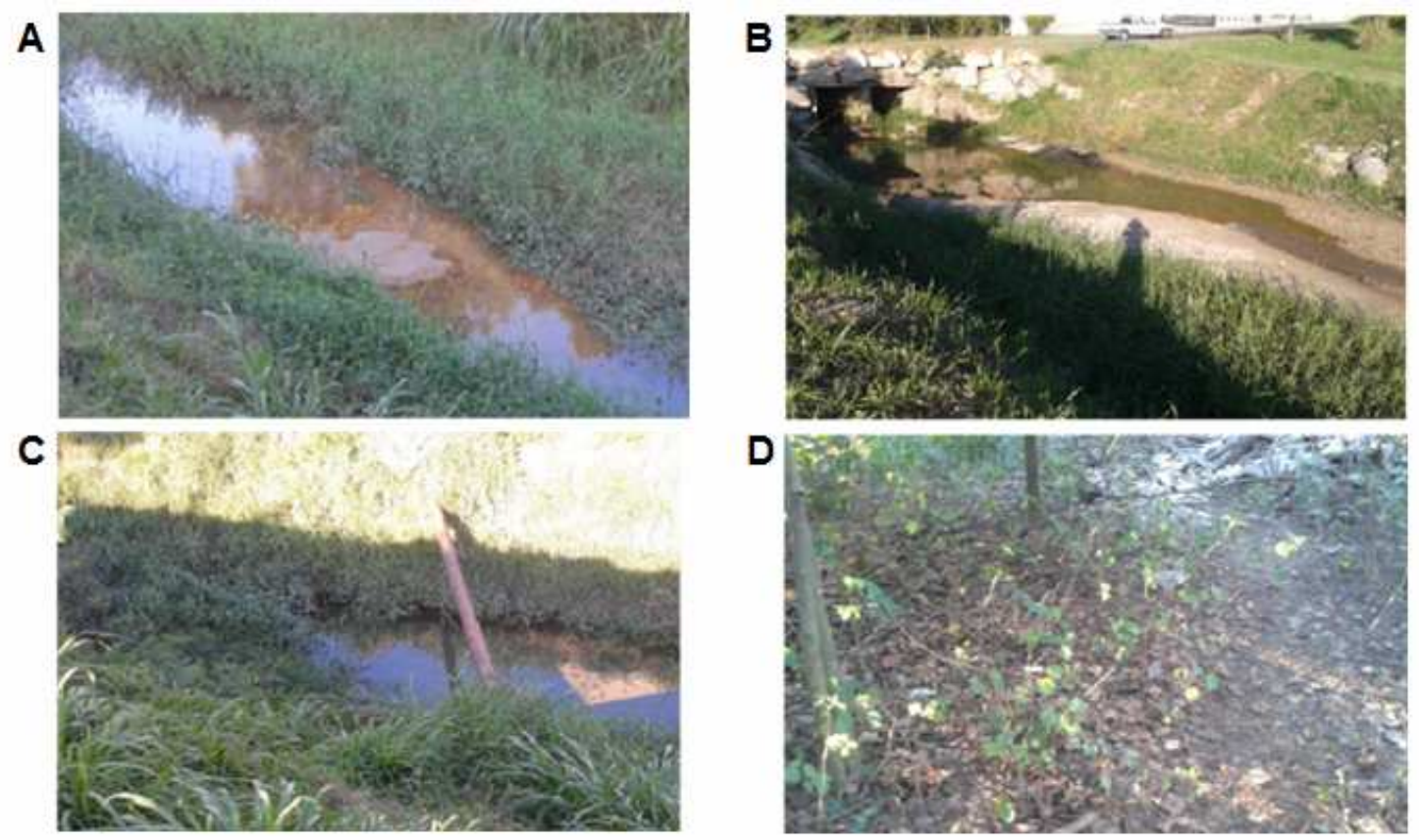

FIGURA 3. Diagnóstico da área a ser recuperada, Rio Sorocaba, bairro Jd. Morumbi (Sorocaba - SP): (a) acúmulo de sedimentos no fundo; (b) menor volume de água; (c) tubulações expostas; e (d) regeneração natural do fragmento florestal. (Elaboração: autores)

A vegetação ciliar possui grande relevância para a conservação dos atributos físicos e químicos do solo. Sobre os aspectos físicos, a vegetação atua como barreia ao impacto da chuva diminuindo a desestruturação do solo e o carreamento de sedimentos para os rios (OLIVEIRA et al., 2003). A redução dos impactos da água da chuva é causada pela ação de folhas e galhos que interceptam as gotas, bem como, pela formação de serapilheira que reduz a velocidade do escoamento sobre a superfície do solo (CASTRO et al., 2013). Assim, quanto maior a degradação da vegetação menor será sua eficiência em reter estes sedimentos transportados aos rios e maiores os riscos de degradação devido ao assoreamento (BRITO et al., 2009; SANTOS \& SPAROVEK, 2011). Do ponto de vista químico, a vegetação ciliar é um importante fator de entrada de nutrientes no solo via ciclagem de nutrientes. Por meio da deposição de serapilheira e mineralização deste material orgânico, o sistema é capaz de se manter em boas condições de fertilidade permitindo a colonização, regeneração e sustentabilidade do sistema (SILVA et al., 2011).

Alterações nas superfícies do solo de bacias hidrográficas podem influenciar o seu fluxo e nutrientes para as massas de água, resultando em impactos sobre a qualidade da água corrente devido ao aumento da sedimentação, da concentração ENCICLOPÉDIA BIOSFERA, Centro Científico Conhecer - Goiânia, v.13 n.24; p.387 2016 
de nutrientes e de poluentes, além de modificação dos padrões hidrológicos (HARDING et al., 1998; ALLAN, 2004; TANAKA et al., 2016). Neste sentido, as matas ciliares atuam como filtros biológicos, diminuindo a chegada de elementos químicos poluentes, como: fertilizantes, pesticidas, material orgânico e outros agentes, potencialmente eutrofizantes aos cursos d'água (LIMA \& ZÁKIA, 2000).

A retirada da vegetação nativa ou sua substituição por outros tipos de uso tem acelerado os efeitos erosivos. Este fato contribui para o aumento do fluxo de água na superfície, promovendo o assoreamento e a poluição dos cursos d'água e reservatórios. Essa poluição é, em geral, promovida por atividades agropecuárias e de esgotamento sanitário urbano, o que causa a diminuição da qualidade da água (CREPANI et al., 2001).

\section{Levantamento de espécies}

No levantamento florístico próximo à nascente do córrego, uma grande aptidão para regeneração natural de espécies arbóreas foi observada, assim como, uma forte potencialidade como fonte natural de sementes (Figura 3d). As espécies encontradas são, em sua maioria, pioneiras tolerantes ao sol e pouco exigentes quanto às condições de solo (Tabela 1). Essas espécies, em geral, começam o processo de sucessão e possibilitam o estabelecimento de espécies mais exigentes, como aquelas pertencentes ao grupo de não-pioneiras ou clímax (SOUZA et al., 2016). Um exemplo de espécie pioneira é a sangra d'água, espécie típica de regeneração de mata ciliar que contribui no processo sucessional, melhorando as condições do solo (KAGEYAMA et al., 2002).

TABELA 1 Lista das espécies encontradas no levantamento florístico da APP.

\begin{tabular}{|c|c|c|c|c|c|}
\hline Família & Nome vulgar & Nome científico & & & Referência \\
\hline Anacardiaceae & aroeira salsa & Schinus molle L. & $\begin{array}{l}\mathrm{GE}^{1} \\
\mathrm{Oc}^{2} \\
\mathrm{SD}^{3}\end{array}$ & $\begin{array}{l}\mathrm{P} \\
\mathrm{NC} \\
\mathrm{Z}\end{array}$ & $\begin{array}{l}\text { COLMANETTI \& BARBOSA, } \\
2013\end{array}$ \\
\hline Sterculiaceae & Mutambo & Guazuma ulmifolia Lam. & $\begin{array}{l}\text { GE } \\
\text { Oc } \\
\text { SD }\end{array}$ & $\begin{array}{c}\mathrm{P} \\
\mathrm{NR} \\
\mathrm{Z}\end{array}$ & BARBOSA et al., 2015 \\
\hline Malvaceae & Cacau & Theobroma cacao L. & $\begin{array}{l}\text { GE } \\
\text { Oc } \\
\text { SD }\end{array}$ & $\begin{array}{l}\text { NP } \\
\text { NB } \\
Z\end{array}$ & SILVA et al., 2015 \\
\hline Fabaceae & Sibipiruna & $\begin{array}{l}\text { Caesalpinia pluviosa } \\
\text { DC. var. peltophoroides } \\
\text { (Benth.) G.P. Lewis }\end{array}$ & $\begin{array}{l}\text { GE } \\
\text { Oc } \\
\text { SD }\end{array}$ & $\begin{array}{l}\text { NP } \\
\text { NB } \\
\text { AUT; } \\
\text { Z }\end{array}$ & $\begin{array}{l}\text { LELES et al., } 2011 \\
\text { ALMEIDA et al., } 2010\end{array}$ \\
\hline Fabaceae & Leucena & $\begin{array}{l}\text { Leucaena leucocephala } \\
\text { (Lam.) de Wit }\end{array}$ & $\begin{array}{l}\text { GE } \\
\text { Oc } \\
\text { SD }\end{array}$ & $\begin{array}{l}P \\
E \\
\text { AUT }\end{array}$ & MELO-SILVA et al, 2014 \\
\hline Euphorbiaceae & sangra d'água & Croton urucurana Baill. & $\begin{array}{l}\text { GE } \\
\text { Oc } \\
\text { SD }\end{array}$ & $\begin{array}{c}P \\
\text { NR } \\
\text { AUT }\end{array}$ & BARBOSA et al., 2015 \\
\hline Fabaceae & Tipuana & Tipuana tipu (Benth.) Kuntze & $\begin{array}{l}\text { GE } \\
\text { Oc } \\
\text { SD }\end{array}$ & $\begin{array}{l}\mathrm{NC} \\
\mathrm{E} \\
\mathrm{A}\end{array}$ & ALMEIDA et al., 2010 \\
\hline Anacardiaceae & Mangueira & Mangifera indica L. & $\begin{array}{l}\text { GE } \\
\text { Oc } \\
\text { SD }\end{array}$ & $\begin{array}{c}\mathrm{NC} \\
\mathrm{E} \\
\mathrm{Z}\end{array}$ & ALMEIDA et al., 2010 \\
\hline Poaceae & $\begin{array}{l}\text { capim- } \\
\text { gordura }\end{array}$ & Melinis minutiflora P. Beauv. & $\begin{array}{l}\text { GE } \\
\text { Oc } \\
\text { SD }\end{array}$ & $\begin{array}{c}\mathrm{NC} \\
\mathrm{E} \\
\mathrm{A}\end{array}$ & MARTINS et al. 2009 \\
\hline
\end{tabular}

Nota: ${ }^{1}$ Grupo ecológico (GE): P - Pioneira, NP - Não pioneira; ${ }^{2}$ Ocorrência (Oc): E - exótica, NR nativa regional, NB - nativa do Brasil; ${ }^{3}$ Síndrome de Dispersão (SD): A - Anemocórica; AUT Autocórica; Z - Zoocórica; NC - não classificada. 
Dentre as espécies inventariadas foram encontradas espécies nativas da região, nativas do Brasil e exóticas (Tabela 1). As principais exóticas encontradas são classificadas como invasoras: leucena e capim-gordura. Essas espécies apresentam alto potencial de germinação e rápido crescimento, o que as tornam altamente agressivas, causando a exclusão de espécies nativas devido a sua alta competitividade (MARTINS et al., 2004; SILVA et al., 2013; MELO-SILVA et al., 2014). Por sua grande agressividade, a leucena, por exemplo, está entre as 100 principais plantas invasoras, segundo a União Internacional da Conservação da Natureza (IUCN). Por isto, torna-se indispensável tomada de decisão visando a minimização dos impactos e controle de espécies que possam representar perigo às espécies naturais da região.

Parte da vegetação nativa de Sorocaba está distribuída em 2.771 fragmentos florestais, dos quais cerca de 50\% se encontram em APP's (MELLO, 2014). A fragmentação reduz o tamanho e aumenta o isolamento de populações arbóreas, 0 que pode ocasionar na divergência genética e, a longo prazo, produzir efeitos negativos para a persistência de espécies (TEMPLETON et al., 1990). O fluxo genético é determinado pelo grau de isolamento entre fragmentos e pela diversidade de fontes de sementes e pólen (SORK \& SMOUSE, 2006). Neste sentido, fragmentos pequenos são importantes para reduzir a distância entre os fragmentos maiores (RIBEIRO et al., 2009), contribuindo para conservação da diversidade genética. Assim, a conservação e manutenção de APP's são essenciais para manter a conectividade entre os fragmentos florestais do município de Sorocaba garantindo a conservação genética das espécies da região.

\section{Uso e cobertura da área}

Parte da área de APP está ocupada por uso urbano-industrial, correspondendo a cerca de $13 \%$ de áreas impermeabilizadas (Tabela 2). Entretanto, cerca de $10 \%$ da área de estudo não são consideradas legalmente como APP e se mantém permeável com cobertura florestal. A área ao entorno do afluente apresenta cerca de $8 \%$ de áreas sujeitas à erosão, $63 \%$ coberta por vegetação arbórea e 29 \% coberta por gramíneas (Figura 5). O zoneamento permitiu determinar as áreas prioritárias para a recuperação, que somam quase $40 \%$ da área total, correspondendo a cerca de 3,7 hectares para enriquecimento da vegetação com espécies locais.

TABELA 2 Classificação de uso da APP na área de estudo.

\begin{tabular}{lc}
\multicolumn{1}{c}{ Classe } & Área (ha) \\
\hline Urbano-industrial & 0,1 \\
Cobertura Florestal & 6,2 \\
Solo exposto & 0,8 \\
Gramíneas & 2,9 \\
\hline
\end{tabular}




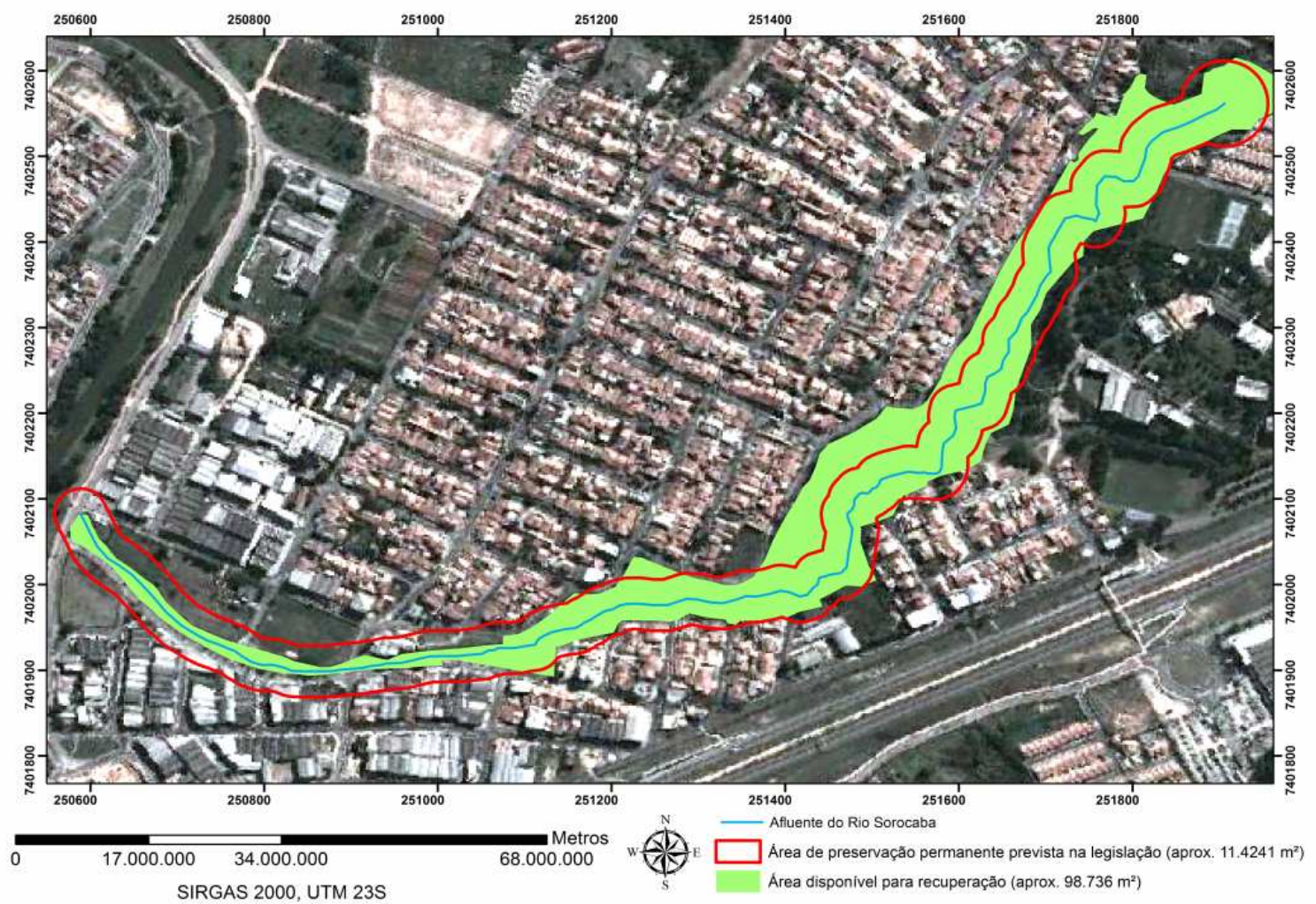

FIGURA 4. Adequação ambiental da APP - bairro do Morumbi (Sorocaba - SP). (Elaboração: autores)

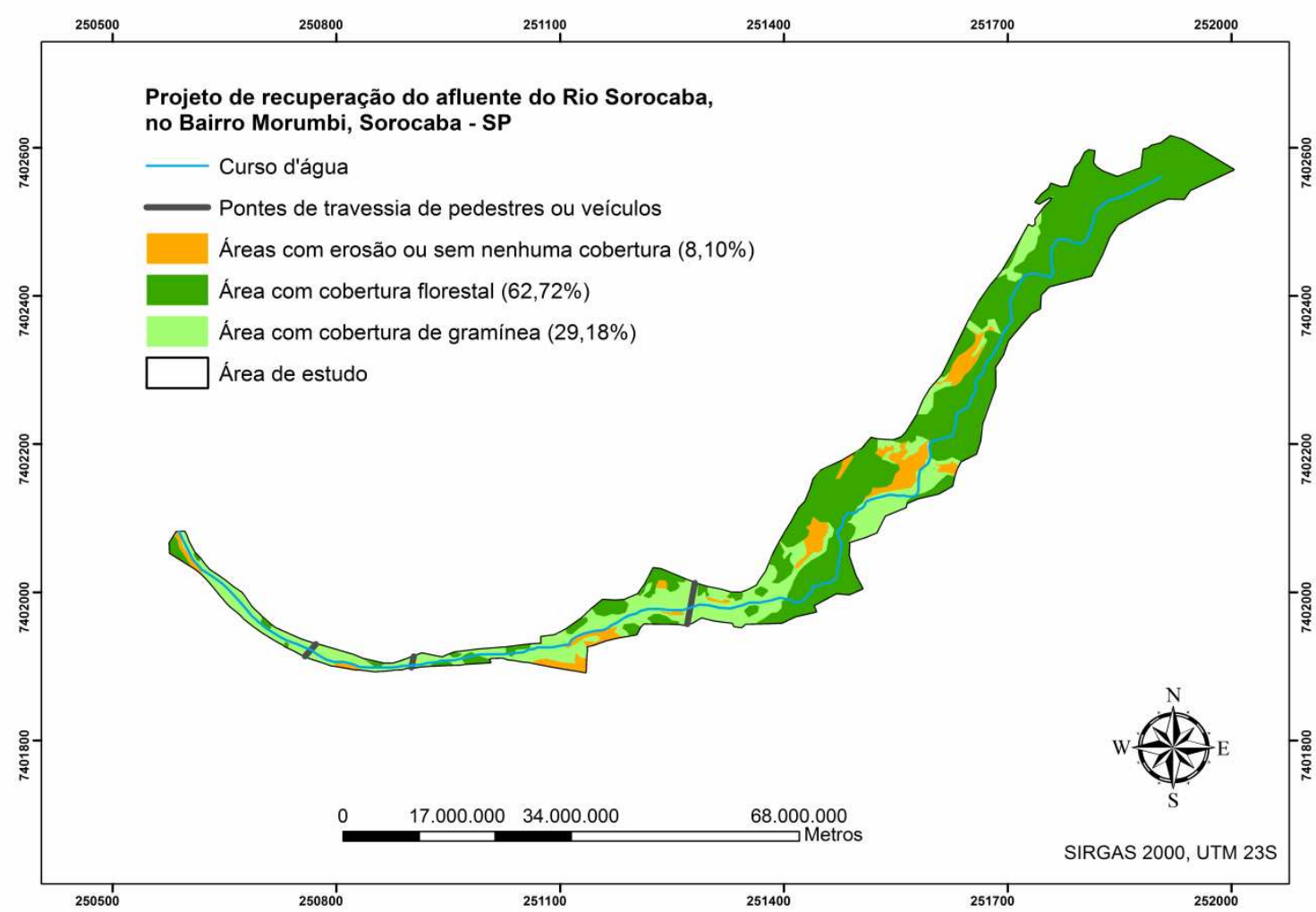

FIGURA 5. Mapa de uso e cobertura do solo na área ciliar do afluente do Rio Sorocaba, no bairro do Morumbi (Sorocaba - SP). (Elaboração: autores) 
No Brasil, o percentual da população que reside em áreas urbanas chega a 80 \% (IBGE, 2010). Esse processo contínuo de urbanização gera paisagens cada vez mais homogêneas, com alto grau de fragmentação de hábitat, causando a perda de biodiversidade e das dinâmicas ecológicas que, por consequência, diminui a disponibilização de serviços ecossistêmicos (MELLO et al., 2014).

Segundo MELLO (2014), em Sorocaba existem cerca de 8,5 mil ha de APP's, o que corresponde a $19 \%$ da área do município. Dessa área, menos de $50 \%$ possui cobertura vegetal, o restante encontra-se sob influência de atividades agrícolas e ocupação urbana. Esta cobertura vegetal remanescente está associada aos corpos hídricos, ou seja, áreas de difícil acesso à ocupação humana, padrão comum encontrado na Mata Atlântica.

Segundo a SECRETARIA MUNICIPAL DE MEIO AMBIENTE DE SOROCABA (2014) as manchas de vegetação do município tendem a permanecer próximas às várzeas, fundos de vale e áreas alagáveis. Esse cenário se destaca na área central da cidade, na qual todos os remanescentes encontram-se a menos de 300 metros de algum corpo de água. O maior déficit de vegetação em APP's está entre a região sul-centro. Isto porque nesta região encontra-se a avenida Dom Aguirre, umas das maiores vias de tráfego de veículos da cidade.

As APP's preservadas no município representam $50 \%$ dos remanescentes de vegetação natural. Segundo MELLO (2014), para o cumprimento total da legislação vigente seria necessário a restauração de cerca de 4 mil ha o que corresponde a 49 $\%$ das APP's. Essa recuperação representaria um aumento de $11 \%$ de áreas naturais, ou seja, a cobertura vegetal do município passaria de $17 \%$ para $28 \%$ (MELLO, 2014).

Para auxiliar o alcance das metas de recuperação, Sorocaba traz em no plano diretor diversas ações que incentivam o reflorestamento e à proteção de matas ciliares. Estas ações priorizam a preservação e recuperação de APP's, mapeiam cabeceiras e áreas críticas nas encostas, apoiam levantamentos de demandas regionais por mudas de espécies florestais nativas para a implantação de viveiros regionais de proteção, e apoiam programas de recuperação das áreas ciliares e programas de controle de erosão (SEMA, 2014).

A expansão do município deve ser feita de maneira planejada conjuntamente com a conservação de áreas naturais, integrando os instrumentos legais vinculados aos aspectos ambientais, sociais e econômicos (MELLO et al., 2014). A atual falta de áreas florestais no município gera a necessidade de ações visando a conservação ecológica dos remanescentes. Desta forma, a recuperação da área em estudo seria interessante do ponto de vista ambiental, pois traria benefícios hidrológicos sobre a qualidade e quantidade de água, e à comunidade, dando melhores condições de aproveitamento do espaço verde urbano. Assim, uma alternativa para a recuperação das margens do curso d'água é o enriquecimento das chamadas áreas prioritárias com espécies arbóreas nativas da região.

\section{CONCLUSÃO}

O levantamento florístico apontou que, apesar do potencial de regeneração natural da área, há uma grande quantidade de espécies exóticas e invasoras, sendo necessário a intervenção profissional capacitada para o planejamento de ações corretivas. Existem cerca de 3,7 ha das chamadas áreas prioritárias, ou seja, áreas 
passíveis de recuperação e que apresentam importância estratégica na mitigação dos efeitos da degradação ambiental constatada no diagnóstico.

\section{REFERÊNCIAS}

AB'SÁBER, A. N. Vale do Paraíba, Serra da Mantiqueira e arredores de São Paulo. Rio de Janeiro: Conselho Nacional de Geografia, 1958.

ALLAN, J.D. Landscapes and riverscapes: the influence of land use on stream ecosystems. Annu. Rev. Ecol. Syst. n. 35, p. 257-284, 2004.

ALMEIDA, R. F. de; SORDI, S. J. de; GARCIA, R. J. F. Aspectos florísticos, históricos e ecológicos do componente arbóreo do Parque da Independência, São Paulo, SP. Revista da Sociedade Brasileira de Arborização Urbana, v.5, n.3, p.18-41, 2010.

ATTANASIO, C. M.; GANDOLFI, S.; B.; ZAKIA, M. J. B.; VENIZIANI JUNIOR, J. C. T.; PAULA LIMA, W. de. A importância das áreas ripárias para a sustentabilidade hidrológica do uso da terra em microbacias hidrográficas. Bragantia, v. 20, n. 10, p.1-9, 2011.

BARBOSA, L. M.; SHIRASUNA, R. T.; LIMA, F. C. de; ORTIZ, P. R. T. Lista de espécies indicadas para restauração ecológica para diversas regiões do Estado de São Paulo. Anais do VI Simpósio de Restauração Ecológica. 2015.

BRITO, R. N. R. de; ASP, N. E.; BEASLEY, C. R.; SANTOS, H. S. S. dos. Características sedimentares fluviais associadas ao grau de preservação da mata ciliar - Rio Urumajó, Nordeste Paraense. Acta Amazônica, v. 39, n.1, p.173-180, 2009.

CASTRO, M. N.; CASTRO, R. M.; SOUZA, P. C. de. A importância da mata ciliar no contexto da conservação do solo. Revista Eletrônica de Educação da Faculdade Araguaia, n. 4, p. 230-241, 2013.

CHAVES, H. M. L.; SANTOS, L. B. dos. Ocupação do solo, fragmentação da paisagem equalidade da água em uma pequena bacia hidrográfica. Revista Brasileira de Engenharia Agrícola e Ambiental, v. 13, (Suplemento), p. 922-930, 2009.

CIELO FILHO, R.; SANTIN, D. A. Florística e estrutura de um fragmento florestal urbano - Bosque dos Alemães, Campinas, SP. Revista Brasileira de Botânica, v. 25, n. 3, p. 291-301, 2002.

COLMANETTI, M. A. A.; BARBOSA, L. M. Fitossociologia e estrutura do estrato arbóreo de reflorestamento com espécies nativas em Mogi-Guaçu, SP, Brasil. Hoehnea. v. 40, n .3, p. 419-435, 2013.

CREPANI, E.; MEDEIROS, J. S.; FILHO, P. H.; FLORENZANO, T. G.; DUARTE, V.; BARBOSA, C. C. F. Sensoriamento remoto e geoprocessamento aplicados ao 
zoneamento ecológico- econômico e ao ordenamento territorial. São José dos Campos: INPE, 2001.

DE MELLO K.; PETRI L.; CARDOSO-LEITE E.; TOPPA R.H. Cenários ambientais para o ordenamento territorial de áreas de preservação permanente no município de Sorocaba, SP. Revista Árvore, v. 38, n. 2, p. 309-317, 2014.

FENGLER, F. H., MORAES, J. F. L. de; RIBEIRO, A. I.; PECHE FILHO, A., STORINO, M.; MEDEIROS, G. A. de. Qualidade ambiental dos fragmentos florestais na Bacia Hidrográfica do Rio Jundiaí-Mirim entre 1972 e 2013. Revista Brasileira de Engenharia Agrícola e Ambiental, v. 19, n. 4, p. 402-408, 2015. Disponível em: <http://dx.doi.org/10.1590/1807-1929/agriambi.v19n4p402-408>.

FREY, H. Urbanização e dinâmica demográfica em Sorocaba, SP. In: D'ANTONA, Álvaro de OLIVEIRA; CARMO, Roberto Luiz. (Org.). Dinâmicas demográficas e ambiente. 1ed. Campinas: Nepo/Unicamp, v. 1, p. 45-62, 2011.

GOLDEMBERG, J.; BARBOSA, L. M. O meio Ambiente no Brasil e no mundo. 2004. Disponível em: <www.ibot.sp.gov.br>. Acesso em 20 mai. 2013

HARDING, J. S., BENFIELD, E. F., BOLSTAD, P. V., HELFMAN, G. S., JONES, E. B. D. Stream biodiversity: the ghost of land use past. Proc. Natl. Acad. Sci. U. S. A. v. 95, p.14843-14847, 1998.

INSTITUTO BRASIELIRO DE GEOGRAFIA E ESTATISTICA - IBGE. Atlas Nacional do Brasil Milton Santos. Brasília: 2010.

KAGEYAMA, P. Y.; GANDARA, F. B.; OLIVEIRA, R. E. de ; MORAES, L. Fe. D. de Restauração da mata ciliar: Manual para recuperação de áreas ciliares e microbacias. Rio de Janeiro: Projeto Planágua Semads / GTZ de Cooperação Técnica Brasil-Alemanha, 2002. 104 p. Disponível: <http://goo.gl/btP3M6>. Acesso em 28 de agosto de 2016.

LELES, P. S. dos S.; ABAURRE, G. W.; ALONSO, J. M.; NASCIMENTO, D. F. do; LISBOA, A. C. Crescimento de espécies arbóreas sob diferentes espaçamentos em plantio de recomposição florestal. Scientia Forestalis, v. 39, n. 90, p. 231-239, 2011.

LIMA, W. P.; ZÁKIA, M. J. B. Hidrologia de Matas Ciliares. In: Ricardo Ribeiro Rodrigues; Hermógenes de Freitas Leitão Filho. (Org.). Matas Ciliares: Conservação e Recuperação. 1 ed. São Paulo: EDUSP/FAPESP, p. 33-44, 2000.

MACIEL, M. DE N. M.; WATZLAWICK, L. F.; SCHOENINGER, E. R YAMAJI, F. M. Ecological classification of arboreal species. Revista Acadêmica: ciências agrárias e ambientais, v. 1, n. 2, p. 69-78, 2003.

MADEIRA N. J. Comportamento espectral dos solos. In: MENESES, P. R.; MADEIRA NETTO, J. Sensoriamento remoto: refletância dos alvos naturais. Brasília: UnB, 2001. 
MAGALHÃES, C. S.; FERREIRA, R. M. Áreas de Preservação Permanente em uma microbacia. Informe Agropecuário, v. 21, n. 207, p. 33-39, 2000.

MARTINS, C. R.; LEITE, L. L.; HARIDASAN, M. Capim-gordura (Melinis minutiflora p. beauv.), uma gramínea exótica que compromete a recuperação de áreas degradadas em unidades de conservação. Revista Árvore, Viçosa-MG, v.28, n.5, p.739-747, 2004.

MARTINS, C. R.; HAY, J. D. V.; CARMONA, R. Potencial invasor de duas cultivares de Melinis minutiflora no cerrado brasileiro - características de sementes e estabelecimento de plântulas. Revista Árvore, v.33, n.4, p.713-722, 2009.

MELLO, K.; PETRI, L.; LEITE, E. C.; TOPPA, R. H. Environmental scenarios for land planning of permanent preservation areas in Sorocaba, SP. Revista Árvore. v. $38 \mathrm{n}$. 2, p.309-317, 2014.

MELO-SILVA, C.; PERES, M. P. ; MESQUITA NETO, J. N. ; GONÇALVES, B. B.; LEAL, I. A. B. Biologia reprodutiva de L. leucocephala (Lam.) R. de Wit (Fabaceae: Mimosoideae): sucesso de uma espécie invasora. Neotropical Biology and Conservation, v. 9, p. 9197, 2014.

OLIVEIRA, G. C.; DIAS JÚNIOR, M. S.; RESCK, D. V. S.; CURI, N. Alterações estruturais e comportamento compressivo de um Latossolo Vermelho distrófico argiloso sob diferentes sistemas de uso e manejo. Pesquisa Agropecuária Brasileira, n. 38, p. 291-299, 2003.

PEREIRA, L. S.; GONÇALVES, B. B.; SILVA-NETO, C. de M.; SANTOS, A. L. F. Evolução do Espaço-temporal do uso e cobertura do solo da terra do Ribeirão Piancó em Anápolis - GO. Revista Mirante, Anápolis, v. 7, n.1, p. 1-15, 2014.

PHUA, M.; MINOWA, M. A GIS-based multi-criteria decision making approach to forest conservation planning at a landscape scale: a case study in the Kinabalu Area, Sabah, Malaysia. Landscape and Urban Planning, v. 71, n. 2-4, p. 207-222, 2005.

PINTO, L. V. A, ROMA, T. N de; BALIEIRO, K. R. de C.; Avaliação qualitativa da água de nascentes com diferentes usos do solo em seu entorno. Cerne, v. 18, n. 3, p. 495-505. 2012. Disponível em: http://dx.doi.org/10.1590/S01047760201 2000300018.

PREFEITURA DE SOROCABA. Plano de Arborização Urbana de Sorocaba 20092021. Sorocaba, 2010a. Disponível em: <http://www.meioambientesorocaba.com.br /sema/UserFiles/file/PLANO\%20DE\%20ARBORIZA\%C3\%87\%C3\%830\%202021(1). pdf>. Acesso em: 23 maio 2013.

PREFEITURA DE SOROCABA. Programa de Recuperação de Mata Ciliar e Nascentes de Sorocaba. Sorocaba, 2010b. Disponível em: <http://www.meioam bientesorocaba.com.br/sema/UserFiles/file/MC101\%20sorocaba\%20Prog_\%20Rec_ \%20Mata\%20Ciliar\%20e\%20Nascentes.pdf>. Acesso em: 23 maio 2013. 
RIBEIRO, M. C.; METZGER, J. P.; MARTENSEN, A. C.; PONZONI, F. J. The Brazilian Atlantic Forest: How much is left, and how is remaining forest distributed? Implications for conservation. Biological Conservation, v. 142, n. 6, p. 1141- 1153, 2009.

RICHTER, C.; PEITER, M. X.; ROBAINA, A. D.; SOUZA, A. R. C. de; FERRAZ, R. C.; DAVID, A. F. de. Levantamento da arborização urbana pública de Mata/RS. Revista da Sociedade Brasileira de Arborização Urbana, v. 7, n. 3, p. 88-96, 2012.

SANTOS, D.S. dos; SPAROVEK, G. Retenção de sedimentos removidos de área de lavoura pela mata ciliar, em Goiatuba (GO). Revista Brasileira de Ciência do Solo, n. 35, p. 1811-1818, 2011.

SCORIZA, R. N.; PIÑA-RODRIGUES, F. C. M. Influência da precipitação e temperatura do ar na produção de serapilheira em trecho de Floresta Estacional em Sorocaba, SP. Revista Floresta, v. 44, n. 4, p. 687-696, 2014.

SEADE. Fundação Estadual Sistema de Análise de Dados. Disponível em: <http://www.seade.gov.br/produtos/perfil/perfil.php>. Acesso em: 20 set 2014.

SEMA. Secretaria Municipal de Meio Ambiente de Sorocaba. Plano municipal de conservação e recuperação da Mata Atlântica. 2014. Disponível em: < http://meioambiente.sorocaba.sp.gov.br/gestaoambiental/wp-content/uploads/sites/4 /2015/12/plano-municipal-de-mata-atlanticarev14vidal.pdf>. Acesso em: 21 out 2016.

SILVA, A. M. da; MORAES, M. L. T.de; BUZETTI, S. Propriedades químicas de solo sob reflorestamento ciliar após 20 anos de plantio em área de cerrado. Revista Árvore, v. 35, n. 1, p. 97-106, 2011.

SILVA, R. R.; COELHO, F. T. A.; ANJOS, M.A. dos; VAZ FILHO, V. Controle do Capim-gordura nas Áreas de Recuperação Ambiental da Mineração Corumbaense Reunida (MCR) Corumbá, MS. Biodiversidade Brasileira, v. 3, n.2, p. 237-242, 2013.

SILVA, J. R.; SILVA, R. M. da; MENDES, F. da S.; ARAUJO, C. de S.; OLIVEIRA, M. G. Composição florística da Trilha Ecológica: Construindo Caminhos da educação e conservação florestal no IFPA - Campus Rural de Marabá. Cadernos de Agroecologia, v. 10, n. 3, 2015.

SORK, V. L.; SMOUSE, P. E. Genetic analysis of landscape connectivity in tree populations. Landscape ecology, v. 21, n. 6, p. 821-836, 2006.

SOUZA, A.R.C.; ROBAINA, A.D.R.; PEITER, M.X.; FERRAZ, R.C.; SCHWAB, N.T.; SOUZA, G.R.C.; PINTO, L.M. Identificação das espécies ornamentais nocivas na arborização urbana de Santiago/RS. Revista da Sociedade Brasileira de Arborização Urbana, v.6, n.2, p.44-56, 2011. 
SOUZA, J. L de; RIOS, A. E. R.; NASCIMENTO, E. M.; FONSECA, G. O.; MACEDO, J. L. A de; VIANINI, K. N.; ALMEIDA, T. L. N. de. Recuperação da área degradada e planejamento ambiental do Parque Gentil Diniz - Contagem/MG. E-xacta, v. 9, n. 1, p. 63-78. 2016. Disponível em: <http://dx.doi: 10.18674/exacta.v9i1.1767>

TANAKA, M. O.; SOUZA, A. L. T.; MOSCHINI, L. E.; OLIVEIRA, A. K. Influence of watershed land use and riparian characteristics on biological indicators of stream water quality in southeastern Brazil. Agriculture, Ecosystems and Environment. v. 216, p. 333-339, 2016.

TEMPLETON, A. R., SHAW, K., ROUTMAN, E., DAVIS, S. K., 1990. The genetic consequences of habitat fragmentation. Annals Missouri Botanical Garden, v 77, $\mathrm{n}$ 1, p. 13-27, 1990.

TUCCI, C. E. M. Águas urbanas. Estudos avançados, v.22, n.63, p. 93-112, 2008 Disponível: <http://dx.doi.org/10.1590/S0103-40142008000200007>

VALENTE, R. O. A; VETTORAZZI, C. A. Definition of priority areas for forest conservation through the Ordered Weighted Averaging method. Forest Ecology and Management, v. 256, p. 1408-141, 2008.

VAN DER PIJL, L. Principles of dispersal in higher plants. 3 ed. Springer-Verlag, Berlin. 1982. 